Gender, Place \& Culture

A Journal of Feminist Geography

ISSN: 0966-369X (Print) 1360-0524 (Online) Journal homepage: https://www.tandfonline.com/loi/cgpc20

\title{
Occupational genders and gendered occupations: the case of water provisioning in Maputo, Mozambique
}

\section{Cecilia Alda-Vidal, Maria Rusca, Margreet Zwarteveen, Klaas Schwartz \& Nicky Pouw}

To cite this article: Cecilia Alda-Vidal, Maria Rusca, Margreet Zwarteveen, Klaas Schwartz \& Nicky Pouw (2017) Occupational genders and gendered occupations: the case of water provisioning in Maputo, Mozambique, Gender, Place \& Culture, 24:7, 974-990, DOI: 10.1080/0966369X.2017.1339019

To link to this article: https://doi.org/10.1080/0966369X.2017.1339019

Published online: 20 Jun 2017.

Submit your article to this journal $₫$

Џلll Article views: 230

View Crossmark data ¿

Citing articles: 3 View citing articles 5 


\title{
Occupational genders and gendered occupations: the case of water provisioning in Maputo, Mozambique
}

\author{
Cecilia Alda-Vidala (D), Maria Rusca ${ }^{b}(\mathbb{D})$, Margreet Zwarteveenc, (D), \\ Klaas Schwartz ${ }^{\mathrm{c}, d}$ (D) and Nicky Pouw ${ }^{d}$ (D)
}

aSustainable Consumption Institute and Geography, University of Manchester, Manchester, UK;

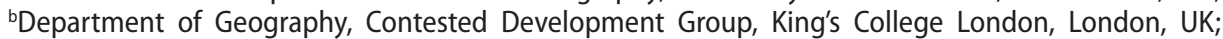
Integrated Water Systems and Governance, UNESCO-IHE Institute for Water Education, Delft, The Netherlands; 'Governance and Inclusive Development, University of Amsterdam, Amsterdam, The Netherlands

\begin{abstract}
Taking issue with how associations between technical prowess or entrepreneurship and masculinity tend to be taken for granted or are seen as stemming from natural or intrinsic gender differences, over the last two decades feminist scholars have developed theoretical approaches to understand the gendering of professions and abilities as the performative outcome of particular cultures and histories. We build on these insights to explore how associations between masculinities, technology and entrepreneurship shape ideas and practices of small-scale water provision in Maputo. Our findings show how activities (i.e. technical craftsmanship, hard physical work) or abilities (i.e. risktaking, innovativeness) regarded as masculine tend to be considered the defining features of the profession. This shapes how men and women make sense of and talk about their work, each of them tactically emphasizing and performing those aspects best fitting their gender. Our detailed documentation of men's and women's everyday involvements in water provisioning challenges the existence of sharp boundaries and distinctions between genders and professional responsibilities. It shows that water provisioning requires many other types of work and skills and male and female household members collaborate and share their work. The strong normative-cultural associations between gender and water provisioning lead to a distinct underrecognition of women's importance as water providers. We conclude that strategies to effectively support small-scale water businesses while creating more space and power for women involved in the business require the explicit recognition and re-conceptualization of water provisioning as a household business.
\end{abstract}

\section{ARTICLE HISTORY}

Received 3 March 2016

Accepted 8 February 2017

\section{KEYWORDS}

Technology;

entrepreneurship; small

scale water providers (SSIP);

urban water supply; Maputo; occupational masculinities and femininities 


\section{Introduction: occupational masculinities and femininities}

Occupational activities and professions are often allocated a masculine or feminine identity, following gendered ideological imaginaries consisting of rather fixed and mutually exclusive binaries. Technical occupations tend to be perceived as'masculine', whereas caring occupations are often labelled as 'feminine'. Such associations have implications for how women and men engage in productive occupations, but also recursively shape gender and professional identities. Because of such recursive connections, the question of how professional and gender identities co-constitute each other has been an important theme in feminist studies. Although few of those have focused on the water sector, the masculinity of this professional domain has not gone unnoticed. Analyses suggest that assumptions of gender neutrality often hide or normalize the numerical dominance of men as professional water actors, while also making gender difference itself disappear as a concern (Laurie 2005, 2011; Zwarteveen 2011). Most policies and documents in the irrigation sector, for instance, do not openly identify main actors as men and merely assume they are (Zwarteveen 2011,41). Other studies have highlighted how prevailing definitions of water-work and gender identities are articulated and performed through spatial and symbolic binary boundaries. Women tend to be associated with the private or domestic domain and recognized as being responsible for fetching water for drinking, bathing and cooking or watering home gardens, while men are linked to the public or productive domain and seen as being responsible for the 'real work' of irrigating and participating in management decisions (Van Houweling 2015; Zwarteveen and Bennett 2004). The tenacity of this public/masculine -private/ feminine distinction also explains why attention to gender in water often translates into a focus on women as domestic water providers, to the neglect of their many other water roles (Sultana 2009; Zwarteveen and Bennett 2004).

The focus of this article on women working as small scale independent water providers (SSIPs) itself challenges prevailing water-gender associations in policy discourses. The article examines the relation between gender and water provision in peri-urban contexts. By comparing women's experiences to those of men, we explore and discuss how masculinities and femininities play out in this occupational activity.

\section{The masculine, the technical, and the entrepreneurial}

Over the past two decades, feminist scholars have spent much intellectual effort in analysing the strong associations between masculinity and technology, and between masculinity and entrepreneurship, showing how specific ways of counting and valuing activities as either technological or entrepreneurial have worked to make women go unnoticed and be undervalued (Ahl and Marlow 2012; Beaton et al. 2015). They have conceptualized the linkages between technology and gender as a continuous re-negotiation of gendered identities and scientific or 
technological rationalisms. Gender and technology are, thus, co-constitutive: neither gender nor technology pre-exist history or analysis, nor is the relation between the two immutable (Bebbington 2002; Faulkner 2000, 2001; Lohan and Faulkner 2004; Rathgeber 2000; Wajcman 2009). Indeed, society's 'relationship to technology is integral to the constitution of subjectivities for both sexes' (Wajcman 2009, 145). Technologies play a role in the constitution of gender, shaping masculine and feminine identities and relations between women and men (Lohan and Faulkner 2004). In the field of water, such insights have been used to establish how masculinity and professional engineering identities 'have come to constitute and define each other, at symbolic and metaphorical levels' (Udas and Zwarteveen 2010, 94). Studies have also shown that attributes connected to what in many cultures are understood as masculine values often come to characterize how water professionals (should) engage with water (Davidson and Stratford 2007; Pavia and Mason 2001) and co-define who controls access to the technology (Van Houweling 2015).

Feminist scholarship in the field of entrepreneurship has conceptualized entrepreneurship as a socially defined and historically constructed phenomenon. As scholars argue, this construction has been informed by normative ideas that narrowly delimit who is seen and recognized as an entrepreneur (Ahl and Marlow 2012; Bourne and Calás 2013; Drakopoulou Dodd and Anderson 2007; Hamilton 2004). The work of heterodox economists in particular has proposed a view of 'entrepreneurship' that is grounded in a definition of the economy itself as a social and instituted process (Lawson 2003; Lee 2010; Pouw and McGregor 2014; Vossenberg 2013). Such conceptualizations have questioned an idea of entrepreneurship that reproduces deeply masculine norms of professionalism and success, including that of entrepreneurs as risk taking, courageous, daring, ambitious and heroic individuals (Aidis et al. 2007; Ahl and Marlow 2012; Bourne and Calás 2013; Drakopoulou Dodd and Anderson 2007; Hamilton 2004). As Bruni, Gherardi, and Poggio $(2004,408)$ argue 'entrepreneurship is historically located in the symbolic universe of the male', while'hegemonic masculinity is also embodied in the figure of the entrepreneur'. Assumptions on masculinity and individualism that inform such definitions of entrepreneurship limit 'the possibilities of who can claim the subject position of entrepreneur' to some men (Ahl and Marlow 2012, 544), making it difficult for many entrepreneurial women and other men to recognize themselves as true entrepreneurs and be recognized as such by the society at a large.

Further, the overemphasis in policy and popular understandings of entrepreneurship as an individualistic practice or as the outcome of distinct personality features makes it difficult to recognize the social context and conditions that help shape entrepreneurial success, or to appreciate how entrepreneurship may consist of 'networked individuals and the networking of individuals' (Drakopoulou Dodd and Anderson 2007, 350). Dominant definitions of entrepreneurship permeate and help sustain hierarchical patterns of gender difference, while also misrepresenting collective family businesses, developed jointly by male and female family 
members, as consisting mainly of one male individual considered the leader and manager (Hamilton 2004).

Instead of accepting technology or entrepreneurship as something intrinsically masculine, we draw inspiration from these feminist studies to examine how, through which processes and mechanisms, technical prowess or entrepreneurial success have come to reflect and help constitute larger cultural systems of valuation and language that define hegemonic masculinity (Faulkner 2001; Lohan and Faulkner 2004; Wajcman 2000). Our starting point thus is a questioning of why men's affinity with technology or entrepreneurship comes to be seen as integral to the constitution of both male gender identity and the cultures of technology and entrepreneurship (Ahl and Marlow 2012; Wajcman 2000).

In our own analysis of SSIPs in Maputo, we make use of notions of performativity to deal with these questions. Within the social sciences, performativity has become a way to create critical awareness of the metaphysical or positivist presumptions of categories, drawing attention to the diverse cultural mechanisms through which these categories come into being (Butler 1988). People act upon ideas about what they think constitutes appropriate masculine or feminine behaviour, 'restoring' or 'twice-behaving' those ideas both through their own behaviour and by assigning them to the behavioural practices of other people (Schechner 2004, 2006). Gender, just like professionality, is 'performed' (in public) like a theatre play on stage, with people becoming men or women, or professionals, by following more or less clear scripts, re-enacting gender and professional identities and relations in the process.

These notions are useful to counter forms of normativity or essentialism often seen in water literature that take for granted or prescribe what it means to be a water provider, a man or a woman. They allow describing both gender and water provisioning as continued processes of becoming. The question we focus on is how, through which expressions and activities, genders and water providers become culturally defined and established as identities, partly also co-shaping each other.

\section{Is small-scale water provisioning agendered?}

In cities in the Global South, SSIPs have since long existed next to much better studied and known public forms of water service provision (Ahlers, Schwartz, and Perez Guida 2013; Kariuki and Schwartz 2005; Njiru 2004; Schaub-Jones 2008; Solo 1999). Since the 1990s, there has been a gradual surge in policy and research attention to the potential of SSIPs in helping serve the poorest areas of cities in the global South (Kariuki and Schwartz 2005; Njiru 2004; Schaub-Jones 2008; Solo 1999). Authors particularly emphasize and praise the entrepreneurial nature of SSIPs (Njiru 2004, 445), their demand responsiveness (Solo 1999, 124) and capacity for innovation (Schaub-Jones 2008). SSIPs are believed to be intrinsically motivated to expand services, to be able to operate without subsidies, and to easily adapt to local conditions (Schaub-Jones 2008). 
What is striking is that this literature is gender-blind. Most articles speak in general terms of water providers, operators, and vendors as if these are gender-less people or as if their gender does not matter. Few, if any pay attention to the gender dynamics of water provisioning. Our own study was motivated by the suspicion that the appearance of gender neutrality works to hide gender hierarchies and inequities. In particular, we feared that through the use of definitions of professional normalcy in implicitly masculine terms, the activities and skills of women would become invisible or appear as less important.

\section{Methodology}

Maputo was selected as a research location because of the importance and particularities of small-scale water provision here, making it into a suitable location to explore the relationship between gender, entrepreneurship and technology in the water supply sector. SSIPs in Maputo are relatively large and many. There are more than 800 water provision systems which require high investment costs and involve the operation of sophisticated technological infrastructures (Schwartz et al. 2015). SSIPs in Maputo operate like small water companies. They abstract water from the ground by means of electric pumps, store it in tanks and convey the water by gravity to in-house or yard connections through a network-like system of pipes.

Data were collected through semi-structured interviews with women and men involved in the small-scale water provision sector in different roles (owners, workers, and family members). The focus was on businesses that were already established and had a for profit vision. Although some of the SSIPs interviewed started their activity with a smaller scale and had grown over time, we have not focused on this business transition. Questions were open-ended and designed to explore the different subjective experiences. All names of participants have been changed for privacy reasons

\section{Gender norms and gendered occupations in Southern Mozambique}

In southern Mozambique, a particular hegemonic patriarchal and masculine culture constitutes an element of continuity between colonial and postcolonial regimes (Sheldon 2003; Tvedten 2010). Portuguese colonial elites saw women's 'emancipation' as consisting of a shift from the burden of 'masculine' agricultural work to household occupations (Arnfred 2004). Although challenging gender stereotypes and hierarchies, women's active participation in both the liberation and the civil war did not translate into longer-lasting changes in terms of the division of labour or intra-household power relations (Tvedten 2010). Since the 1990s, development projects in Mozambique have increasingly emphasized gender mainstreaming and women's entrepreneurship. Yet, and perhaps because of their reluctance or inability to address more structural inequities, these initiatives have failed to alter existing intra and inter household power dynamics or the reproduction of gendered social 
subjectivities through women's and men's daily economic activities (ILO-WEDGE 2011; Sheldon 2003; UNIDO 2007). Women still face multiple gendered barriers to engage in both formal and informal occupations. The majority of women are employed in small-scale family businesses - such as street vending - requiring low education levels and investment costs and mostly operating at the periphery of the informal economy (Agadjanian 2002; Sheldon 2003).

\section{The discursive framing of SSIPs in Maputo}

\section{Characteristics of SSIPs in Maputo}

SSIPs in Maputo have specific characteristics, which have important implications for the ways in which women and men perform their participation in the sector. First, most businesses are household and homestead-based. SSIPs often originated in response to household needs: in areas where water supply was not available, families that could afford it arranged their own supply by drilling a borehole and installing a tank in their backyard. After realizing the income generating potential, many transformed this household 'self-help solution' into a water provisioning business by installing additional infrastructure to sell water to neighbours. Thus, many SSIPs are located in or close to the residence of the owners. Secondly, smallscale water businesses in Maputo require a relatively large investment. The cost of drilling a borehole and installing the necessary infrastructure can vary from $€ 10.000-€ 45.000$ (Tutusaus 2013). These start-up costs restrict entry in the market to those households able to generate sufficient financial resources. Third, the operation of small water companies includes a variety of activities, which range from managerial (e.g. billing, revenue collection, customer relations) to technical (e.g. repairs and maintenance, establishment of new connections, expansion of infrastructures). Where some of these activities involve daily operations, others only should be done once every month (e.g. billing), and yet others only occur sporadically (e.g. repairing in case of breakages). Running a water provisioning business is not a full-time engagement, making it possible to combine it with other responsibilities inside or outside the household. Last, developing a small-scale water provisioning business in Maputo requires the concerted and networked support of different people and organizations. Accessing knowledge and information, mobilizing funds, attracting customers and keeping them happy requires SSIPs to draw 'on their capacity to mobilize different resources and skills, and the networks they participate in' (Schwartz et al. 2015, 34). The money to start up the business is often obtained from savings from formal and informal employment and loans with formal banks, friends, family members, and business partners. Those active in running and employed by the small-scale enterprise often belong to the network of trusted friends and family of the household. Knowledge about how to install, operate and maintain the system comes from experienced providers, the so-called water professors who help new providers to'start-up' (Cappuccini 2014). 


\section{How water provisioning becomes masculine}

In everyday parlance in Maputo, entrepreneurial water provisioning is clearly associated with masculine identity:

traditionally in Africa water has always been managed by women. In many rural and peri-urban areas where there is no piped water, water provision is definitely a feminine task. However, when we add 'business' to this binomial, things change and women are out. (gender specialist, Universidade Eduardo Mondlane)

Both male and female water providers share and reinforce this discursive framing. Assertions as 'it is a job for men' (man, SSIP), 'it is a masculine thing' (woman, SSIP), 'it is a man's job' (woman, SSIP) or 'it is not a work for women' (woman, SSIP) were commonly made to describe this occupational activity. When prompted, the manliness of water provisioning appeared to be grounded in two discourses. First, the job requires the type of physical strengths and technical skills seen as characteristic of masculine identity. Working as a provider is perceived as a'more appropriate job for men: it requires strength, it requires using pliers and wrenches ...' (woman, SSIP). Interviewees described the job as a'hard'or'heavy' activity in which technical knowledge and entrepreneurial skills play an important role:

there are only a few women working in this business because many of the things that it involves are man's things, you need to be strong to work with heavy pipes, to dig for their installation, you need to walk a lot to read the meters, getting the money for the first investment is also quite difficult. (man, SSIP)

Indeed, it is through the characterization of water provisioning as consisting of technical work that it becomes marked as a masculine profession. Ana (woman, SSIP) explains

they [husband and son] have learnt to repair the things by themselves. Men and boys are more curious to learn the technical things. I did not have that curiosity and I think that other women neither have it.

Whilst clearly characterizing water provisioning as a job fitting men better than women, providers also acknowledge that this gendered understanding of roles results from 'norms [that] locate women and men in different positions in society. Traditionally the activities that require more physical work or more relationships with other men are more conveniently done by men' (man, SSIP). By attributing gender differences to traditions, respondents indicate that things are changing. As another provider suggests 'to use pliers, a hammer, or a wrench to fix a tap were traditionally men activities' (woman, SSIP). Local norms create segregation between what women and men do or should do in the business.

The second discourse pertains to masculinity and entrepreneurship. Entrepreneurs are often presented as innovative individuals with an extraordinary ability to take initiative and risks. Stereotypes and normative ideas commonly attribute to men many of the characteristics considered necessary to be a true entrepreneur. They are for instance ascribed as having an adventurous and daring character, in contrast to women who are described as being averse to taking risks: 
'the difference [between women and men] is the initiative. Men usually have more initiative when it comes to start and run a SSIP business' (woman, SSIP). 'The reason why there are more men than women running water provision businesses is just that men are more adventurous' (man, SSIP). The association between entrepreneurship and masculinity explains why women's ability to be or become true entrepreneurs is often directly and indirectly questioned:'people still ask who gave me the idea to start this business, what does it mean? I think they doubt that I could have come up with it on my own' (woman, SSIP). The existence of female water providers is something that requires an explanation. People for instance speculate that women start up a water provisioning business not because of profit-making motives, but because they are prompted by the need to provide for the family: 'if a woman starts a business like this is because she has gone through a difficult situation, she might be alone or she might have the necessity to provide for her family' (woman, SSIP).

In these discursive framings, professional and gender performance become co-constitutive: the job is characterized as masculine based on the association of specific skills and attitudes supposedly needed to be a successful water provider with characteristics often labelled as genuinely distinctive of masculine identity. This framing also implicitly presents productive water provisioning as an individual business, one in which one (male) individual is heading, managing, and maintaining the system. The analysis of the everyday practices of water provisioning businesses, however, shows that this masculine and individualistic imaginary ill captures the diversity of activities and operations needed to keep the business running.

\section{Water service provisioning in Maputo: everyday practices of performance}

\section{The blurred boundaries of the productive and non-productive domains}

A detailed focus on the everyday practices of water provisioning provides a less stereotypically gendered image of what the profession entails, also calling into question the manliness of the business. In most water provisioning businesses, the borehole is located in the residential compound of the owners of the business. This implies that the day-to-day operation of the business de facto often becomes the responsibility of those who happen to be near-by. The physical proximity of the borehole makes relatively logical and easy for women to become involved in the business. A woman for example explained that although her husband started the business, she has 'always accompanied him in the administrative part'. Another woman justified her involvement in the business by explaining that, unlike her husband, she did not work outside the household. Thus, she became the one to be in charge of the business.

Women's engagement goes beyond administrative tasks and does involve so-called entrepreneurial responsibilities, such as everyday negotiations with 
resellers and decision-making on financing. Madalena, for instance, does not see herself as an entrepreneur and explains that her husband owns and is responsible for the water systems. Whilst maintaining that she has no responsibility in the business, she nevertheless tells how her activities include going to the shops to buy materials, negotiating with the sellers, and collecting money from customers. Since customers are used to speaking with her when paying the bill, they also report to her when there is a problem. Madalena also took (risky) financial decisions by borrowing money from a micro finance institution to buy a new tank to expand the business. She did this without consulting her husband:'they came to the house and made a list of my properties'. After receiving the money, she bought the tank and asked the plumber to install it. When her husband arrived home the tank was already installed. Madalena enjoyed the opportunity to speak about her role in the business, and was thankful for the researchers' recognition of her importance. She jokingly said: 'I have seen that I even did more than him'. This anecdote shows that there is a gap between dominant ideas on what entrepreneurship entails, and the everyday practices of managing and strategizing for the business. Dominant notions make it more difficult and less self-evident for women to take (public) pride in and gain recognition for tasks widely perceived as masculine. Performing these tasks might be construed as diminishing their femininity and endanger their reputation. This explains why many women engaging in water provisioning tend to underplay their importance, and construe it as a more or less logical extension of their more appropriately feminine duties as mothers and domestic caretakers. In the process, they reproduce the specific and rather rigid occupational imaginary in which the men own and are responsible for the business, while their own and others' involvement in running the business are made secondary or invisible.

Instead of conceptualizing SSIPs as one person activities, we argue there is merit in describing them as collective family businesses in which the partner, siblings, and other trusted kin all work together. Conversations with men involved in water provisioning support such a conceptualization: Lino (man, SSIP), described how his wife helps when he is not a home. Xavier (man, SSIP) explained he likes his wife to be involved in the daily activities because according to him, she needs to know how to run it to be prepared for when he will not be there anymore. Ownership may also change hands over time, and more hidden roles and responsibilities may become visible:

I have contributed to the business since the beginning because my husband had a job in the catering industry. I was also working but I used to spend more time at home. My husband passed away four years ago, but what I do now and what I used to do in the past has not changed much Ana. (woman, SSIP)

Lucia (woman, SSIP) went through a similar situation. She explains that after her husband passed away her customers and neighbours started to openly wonder if she would be able to continue providing water as when the husband was still alive, even though she had been in charge since the beginning. She proved herself 
as able to perform and has been providing water since 2001. In fact, the absence of a masculine companion in the household seems to make it easier for women to present themselves, and be recognized by customers as, the visible leader of the business.

A focus on the everyday practices of water supply provisioning also challenges often-used boundaries between household (family) and business or between private and public spaces. The household is simultaneously a private (providing the opportunity for women to informally engage) and public location, a space in which domestic and business activities are intertwined. Ownership, roles, and responsibilities in the business are fuzzy and often informally defined, to suit the particular availability, skills and willingness of the members of the household or wider kinship networks enrolled to help running it. Many women started their participation in water supply provisioning almost matter-of-factly, engaging in activities (e.g. receiving customers coming to the house to pay the bills) because they happened to be the ones to be around. Many, however, ended up assuming bigger responsibilities for the smooth running of the water provision company. As they continue considering this work as an extension of their household duties, labelling it as something belonging to the private and family sphere, their importance tends to be overlooked, also by themselves. Both gender and professionalism become continuously re-enacted through the use of such private-public boundaries, with the activities that women do in the business being automatically labelled as belonging to the household (the reproductive or private sphere) and as dissociated from the business (the productive or public space) as this, by definition, is what men do. These boundaries work to conceal the connections and interdependencies between the two domains or spheres, simultaneously hiding women's participation in the sector.

\section{Technology, management, and gender identities}

While discourses mobilized by SSIPs around the manliness of the job are grounded in the assumed physical strength and technical skills of men, a focus on the everyday practices of water provisioning yields a more gender nuanced picture. First, describing the business as dominated by technical activities downplays the importance of many other tasks, which are equally or more prominent and time consuming. These importantly comprise tasks related to the management of the company and maintaining relations with the customers, including billing and revenue collection, following up on non-paying customers and managing customer complaints. Many interviewees stereotype these tasks as more appropriate for women: 'I have two ladies working with me; they do the reading of the metres, prepare the bills and collect the money. I prefer to work with women because they are more reliable in this type of tasks' (woman, SSIP). The preference for women for customer service is grounded in the belief that women 'have more patience with the clients and they are also more accessible for them' (man, SSIP). 
Further, typifying water supply provisioning as importantly consisting of physical and technical tasks suggests that owners spend a lot of time on technical matters. In actual practice, also male business owners often delegate technical activities to trained experts. As Esperança (woman, SSIP) puts it, 'running a water provision business is like driving a car: you do not need to know how the engine works to be able to drive it'. Most of the (male and female) owners of SSIPs do not themselves undertake the technical and physical work, but instead outsource it to employees or plumbers. It is not surprising that none of the respondents had any specific educational background and technical skills. In fact, outsourcing does not imply women's (or men's) incompetence:

there are only few women working as plumbers because they think that it is a'man's job', but if they wanted to do it, they would be able. They do not do it because of laziness. It is because they think is not for them (woman, SSIP).

Antonieta (woman, SSIP), for example, prefers to outsource heavy tasks like excavation, but she fully understands the system and oversees the employees. Esperança (woman, SSIP) explains that the work of a SSIP is a'man's work' because it is hard. She has employees doing the hard work for her. However, she also explains 'when they are not there, I tie my capulana [traditional fabric used by Mozambican women tied around the waist as a skirt] and I do it myself'. Similarly, Alzira explains that throughout the years she has learnt from the plumber how the water system works. She does not do the repairs herself because according to her, it is a 'more appropriate work for men'. Although she is able repair the things herself, she prefers to follow the custom and let them do it.

Also here, gender meanings are not completely rigid. Technical education legitimizes some women to perform what otherwise would be understood as 'man's job'. This is how Nyeleti, (woman, SSIP), a formally educated technician that works for a pump company in the installation and repairing of pumps, can own a water provision business without provoking many questions. Interviewees often presented her as an exception and an example of how education can change things for women. As she has the (technical) knowledge, 'she is able to climb tanks and does not need to ask anyone to do the things for her' (woman, SSIP).

The difference in the way women and men approach and talk about the technical part of the water provisioning activity seems to derive more from the pride each gender can take in doing technical work, than it is a reflection of how much they actually do it. While women tend to hide or downplay their involvement in it 'because they don't want people to tell them that they work as a man' (woman, SSIP), men often take pride in their technical prowess and overstate their participation in technical activities. In reporting about what they do, both the image of water provisioning as an eminently masculine profession and the idea that only men can do technical work become reproduced, with the effect of downplaying the activities labelled as feminine and women's work. 


\section{The myth of the of the daring male entrepreneur}

In contrast with how people tend to explain the oddity of women owning a water supply provisioning business, none of the women starting the business as entrepreneurs said to have started out of 'necessity'. Rather, their motivation often lied in the desire to become independent. Victoria (woman, SSIP)'always wanted to be a business woman', Florinda (woman, SSIP) 'wanted to have a business that kept her busy and gave her some money' or Dulce (woman, SSIP) wanted to have a 'separate source of income and be independent'. Women do not perceive that they lack entrepreneurial skills and are well aware of the income-earning opportunity a water provisioning businesses offers, describing it as relatively low risk and with (potentially) high return rates:

when we started selling water there was no one doing it here, we did it because we were looking for a complementary source of income. [...] We knew water was a good business, profitable, the boreholes do not fail and they last in time so they can be used in the future by our kids. (woman, SSIP)

Rather than risk-aversion, a main barrier to enter this market is capital: 'the difference between this business and others is just the investment; actually, water is more profitable and less risky than breeding roosters [ Income earning activity that in the peri-urban areas of Maputo is traditionally developed by women]' (woman, SSIP). The high investment costs explain why there are fewer women leading water businesses than there are in other small-scale informal businesses requiring smaller capital investments. Mobilizing the needed funds often means dealing with banks that require a guarantee on the investment:

the main problem is that one needs to have something to pawn, otherwise the bank does not give you any money. [...] In addition you have to show that you know for what you need the money and that you understand the business. (woman, SSIP)

Eligibility criteria include having a formal and stable salary or assets to present as collateral. In this regard, women are at a disadvantage. First, the presence of women employed in the formal sector is quite low. Second, the cultural norms locate men as official owners of family assets: 'in general financial conditions of women do not help. They have fewer possibilities for the investment' (woman, SSIP). Lack of assets, properties, and a formal job constitute an obstacle also for the 'informal capital market':

women need to have something in property or a job to be able to get money either from the bank or from friends. They need to demonstrate that they would be able to pay and that does not happen so often. (woman, SSIP)

Definitions invoking the entrepreneur as an adventurous individual suggest he operates in relative isolation from his family and social networks. This is problematic because it contributes to rendering invisible the participation of many women in the sector, but it also deeply misrepresents the actual functioning of businesses. Many SSIPs are family-based businesses in which risks and benefits are shared within the household. The formal owner might be an individual but the 
effort to raise the funds for the first investment often is done jointly, with financial decision making consisting of intra-family negotiations.

\section{Conclusions: myths, imaginaries, everyday practices of productive water provisioning}

This article has shown that small-scale water providers tend to frame their business as belonging to the male sphere trough the symbolic connection between the abilities and skills supposedly needed to run a successful water provision business with the masculine body and identity. SSIPs in Maputo define water provisioning, as something that entails physical work, consists of relationships with other men, and requires strength and curiosity about technical aspects. Similarly, entrepreneurship is considered a men's affair in that it requires innovation, financial management and risk taking. Paradoxically, both male and female providers refute these discursive framings through their everyday involvements in water provisioning. While men often perform the role of owner and decision-maker and occupational femininities are often denied or underplayed, in everyday practices the boundaries between ownership, management, decision-making, and responsibilities become blurred. Women are involved in everyday operation and often informally become the decision-makers and managers of the business.

Our case reveals that normative ideas about the gender of the profession importantly shape how men and women make sense of their water provisioning activities, each of them tactically emphasizing and performing those aspects best fitting their gender. In the process, they re-enact gender identities as well as stereotypical definitions of what the profession entails. The dominant portrayal of the profession as something technical, entrepreneurial and therefore masculine, makes it more difficult for women to draw attention to and take pride in their water provisioning work, as it may make them appear less appropriately feminine. Therefore, they attempt accounting for this work in ways that makes it seem compatible with their womanhood, by referring to it as an extension of their domestic and caring activities. By doing so women risk undervaluing their own importance as water providers, while also making it more difficult for others to recognize or support their contributions. This discursive framing of water provisioning feeds into an already strong policy imaginary of the male entrepreneur, an imaginary which both conceals the network behind (or sometimes in front) of the business and contributes to a misrepresentation of small-scale water provisioning.

Strategies to effectively support SSIPs that simultaneously help create more space and power for women involved in the business require the explicit recognition and re-conceptualization of provisioning as a household business. This will allow for occupational femininities and the 'networked individuals and the networking of individuals' (Drakopoulou Dodd and Anderson 2007, 350) behind the business to be acknowledged, and effectively supported and empowered. 


\section{Acknowledgements}

The authors would like to thank research participants for their time and collaboration and anonymous reviewers for their helpful and constructive comments. This research has been undertaken in the framework of the collaboration between INHAbIT Cities (Investigating Natural, Historical and Institutional Transformations in Cities) and UNHIDE (Uncovering Hidden Dynamics in Slum Environments).

\section{Disclosure statement}

No potential conflict of interest was reported by the authors.

\section{Funding}

INHAbIT Cities is sponsored by the European Union's Horizon 2020 research and innovation programme under the Marie Skłodowska-Curie grant agreement number 656738 and is implemented by King's College London. UNHIDE is sponsored by the Dutch Ministry of Development Cooperation (DGIS) and is implemented under the memorandum of understanding between the University of Amsterdam and the UNESCO-IHE Institute for Water Education.

\section{Notes on contributors}

Cecilia Alda-Vidal is a doctoral student in Human Geography at the University of Manchester's School of Environment, Education and Development. Her research focuses on uneven trajectories of urban sanitation infrastructure development and everyday practices of sanitation and hygiene in Lilongwe, Malawi.

Maria Rusca is a Marie Sklodowska-Curie Research Fellow in the Geography Department at King's College London. Her research project, titled Investigating Natural, Historical and Institutional Transformations in Cities (INHAbIT Cities), aims at improving understandings of the dynamics of basic service provision in urban and suburban spaces in the global South.

Margreet Zwarteveen is Professor of Water Governance at UNESCO-IHE and the University of Amsterdam. Trained as both an irrigation engineer and a social scientist, Margreet is interested in water allocation policies and practices, focusing on questions of (gender-) equity and justice. Her current research includes a project (DoUbt, Deltas' dealings with uncertainty, financed by the Netherlands Organization for Scientific Research, NWO), that looks at the mobility of Dutch Delta experts and expertise to examine the production of evidence under conditions of uncertainty. In her work, Margreet favours an interdisciplinary approach, seeing water allocations as the outcome of interactions between nature, technologies and society.

Klaas Schwartz is Associate Professor Urban Water Governance at the UNESCO-IHE Institute for Water Education and visiting researcher at the Amsterdam Institute for Social Science $h$ of the University of Amsterdam. He is the Head of the Water Services Management Group which focuses on management and governance of water supply and sanitation provisioning. Within this domain his main interests concern reforms of public water utilities and informal water services provisioning.

Nicky Pouw is associate professor in the economics of human development at the Governance and Inclusive Development programme of the University of Amsterdam. She manages several research programmes on inclusive development in Africa and is member of the Scientific 
Council of the African Studies Centre at Leiden University, and guest lecturer at UNESCOIHE, Delft University. She is author of the book An Introduction to Gender and Wellbeing in Microeconomics (2017, Routledge) and co-editor of the book Local Governance and Poverty in Developing Nations (2012, Routledge). She has published many articles and two special issues on inclusive development in peer reviewed international journals.

\section{ORCID}

Cecilia Alda-Vidal (D) http://orcid.org/0000-0001-5128-0012

Maria Rusca (D) http://orcid.org/0000-0003-4513-3213

Margreet Zwarteveen (D) http://orcid.org/0000-0001-7169-1337

Klaas Schwartz (iD) http://orcid.org/0000-0002-9154-7620

Nicky Pouw (iD) http://orcid.org/0000-0002-5406-0282

\section{References}

Agadjanian, Victor. 2002.“Men Doing 'Women's Work': Masculinity and Gender Relations Among Street Vendors in Maputo, Mozambique." The Journal of Men's Studies 10 (3): 329-342.

Ahl, H., and S. Marlow. 2012. “Exploring the Dynamics of Gender, Feminism and Entrepreneurship: Advancing Debate to Escape a Dead End?" Organization 19 (5): 543-562.

Ahlers, R., K. Schwartz, and V. Perez Guida. 2013. "The Myth of 'healthy' Competition in the Water Sector: The Case of Small Scale Water Providers." Habitat International 38: 175-182.

Aidis, Ruta, Friederike Welter, David Smallbone, and Nina Isakova. 2007."Female Entrepreneurship in Transition Economies: The Case of Lithuania and Ukraine." Feminist Economics 13 (2): 157183.

Arnfred, Signe. 2004. “Conceptions of Gender in Colonial and Post-colonial Discourses: The Case of Mozambique." In Gender Activism and Studies in Africa, 108-128. Codesria Gender Series. Dakar: Codesria. http://www.codesria.org/spip.php?article1385

Beaton, Ann M., Francine Tougas, Natalie Rinfret, and Tanya Monger. 2015. “The Psychological Disengagement Model Among Women in Science, Engineering, and Technology." British Journal of Social Psychology 54 (3): 465-482.

Bebbington, Diane. 2002. "Women in Science, Engineering and Technology: A Review of the Issues." Higher Education Quarterly 56 (4): 360-375.

Bourne, Kristina A., and Marta B. Calás. 2013. “Becoming 'Real' Entrepreneurs: Women and the Gendered Normalization of 'Work"' Gender, Work and Organization 20 (4): 425-438.

Bruni, Attila, Silvia Gherardi, and Barbara Poggio. 2004. "Doing Gender, Doing Entrepreneurship: An Ethnographic Account of Intertwined Practices." Gender, Work and Organization 11 (4): 406-429.

Butler, Judith. 1988. "Performative Acts and Gender Constitution: An Essay in Phenomenology and Feminist Theory." Theatre Journal 40 (4): 519.

Cappuccini, Emanuela. 2014. Drivers of Technological Choices for Water Supply Services: The Case of Small Scale Water Providers of Greater Maputo. Delft: UNESCO-IHE Institute for Water Education.

Davidson, Julie, and Elaine Stratford. 2007.“En(gender)ing the Debate About Water's Management and Care - Views from the Antipodes." Geoforum 38 (5): 815-827.

Drakopoulou Dodd, S., and A. R. Anderson. 2007. "Mumpsimus and the Mything of the Individualistic Entrepreneur." International Small Business Journal 25 (4): 341-360.

Faulkner, Wendy. 2000. "The Power and the Pleasure? A Research Agenda for 'Making Gender Stick' to Engineers." Science, Technology \& Human Values 25 (1): 87-119. 
Faulkner, Wendy. 2001. “The Technology Question in Feminism: A View from Feminist Technology Studies." Women's Studies International Forum 24 (1): 79-95.

Hamilton, E. 2004. "Whose Story Is It Anyway? Narrative Accounts of the Role of Women in Founding and Establishing Family Businesses." International Small Business Journal 24 (3): 253-271.

ILO-WEDGE. 2011. “The Enabling Environment For Women In Growth Enterprises In Mozambique." 43.

Kariuki, Mukami, and Jordan Schwartz. 2005. "Small-scale Private Service Providers of Water Supply and Electricity: A Review of Incidence, Structure, Pricing, and Operating Characteristics." No. 3727. World Bank Policy Research Working Paper No. 3727, World Bank Policy Research Working Paper.

Laurie, Nina. 2005. “Establishing Development Orthodoxy: Negotiating Masculinities in the Water Sector." Development and Change 36 (3): 527-549.

Laurie, Nina. 2011. "Gender Water Networks: Femininity and Masculinity in Water Politics in Bolivia." International Journal of Urban and Regional Research 35 (1): 172-188.

Lawson, T. 2003. Reorienting Economics. London: Routledge.

Lee, F. 2010. A History of Heterodox Economics. Challenging the Mainstream in the 20th Century. London: Routledge.

Lohan, M., and Wendy Faulkner. 2004. "Masculinities and Technologies: Some Introductory Remarks." Men and Masculinities 6 (4): 319-329.

Njiru, Cyrus. 2004. "Utility-small Water Enterprise Partnerships: Serving Informal Urban Settlements in Africa." Water Policy 6 (October). IWA Publishing: 443-452.

Pavia, Teresa M., and Marlys Mason. 2001. "Exploring Water Consumption Using a Gender Continuum: The Case of the American West." Academy of Marketing Sciences Review 10: 1-14.

Pouw, N. R. M., and A. J. McGregor. 2014. "An Economics of Wellbeing: What Would Economics Look like If It Were Focussed on Human Wellbeing?" 436. IDS Working Paper, Publisher IDS.

Rathgeber, E. M. 2000. "Women, Men and ICTs in Africa: Why Gender Is an Issue." In Gender and the Information Revolution in Africa, edited by E. M. Rathgeber and E. O. Adera, 17-34. Ottawa: International Development Research Center.

Schaub-Jones, David. 2008. “Harnessing Entrepreneurship in the Water Sector: Expanding Water Services Through Independent Network Operators." Waterlines 27 (4): 270-288.

Schechner, R. 2004. Performance Theory. London: Routledge.

Schechner, R. 2006. Performance Studies: An Introduction. London: Routledge.

Schwartz, Klaas, Mireia Tutusaus Luque, Maria Rusca, and Rhodante Ahlers. 2015. "(In)formality: The Meshwork of Water Service Provisioning." Wiley Interdisciplinary Reviews: Water 2 (1):31-36.

Sheldon, Kathleen. 2003. "Markets and Gardens: Placing Women in the History of Urban Mozambique." Canadian Journal of African Studies/La Revue Canadienne Des Études Africaines 37 (2-3): 358-395.

Solo, Tova Maria. 1999. "Small-scale Entrepreneurs in the Urban Water and Sanitation Market." Environment and Urbanization 11 (1): 117-132.

Sultana, Farhana. 2009. "Fluid Lives: Subjectivities, Gender and Water in Rural Bangladesh." Gender, Place \& Culture 16 (4): 427-444.

Tutusaus, Mireia. 2013. "Negotiating (In)formality Drinking Water Provision in Greater Maputo." MSc thesis. UNESCO-IHE, Delft, The Netherlands.

Tvedten, Inge. 2010. "Gender and Poverty in Mozambique." CMI Brief 9 (6): 4. Bergen: Chr. Michelsen Institute.

Udas, Pranita B., and Margreet Z. Zwarteveen. 2010.“Can Water Professionals Meet Gender Goals? A Case Study of the Department of Irrigation in Nepal." Gender \& Development 18 (1): 87-97. 
UNIDO. 2007. "Mozambique. Investing in a New Generation. Project Factsheet." http://www. unido.org/en/where-we-work/africa/selected-projects/mozambique-entrepreneurshipcurriculum-programme.html.

Van Houweling, Emily. 2015. "Gendered Water Spaces: A Study of the Transition from Wells to Handpumps in Mozambique." Gender, Place \& Culture 22 (10): 1391-1407.

Vossenberg, Saskia. 2013. "Women Entrepreneurship Promotion in Developing Countries: What Explains the Gender Gap in Entrepreneurship and How to Close It?" Maastricht School of Management Working Paper Series, August 2013.

Wajcman, J. 2000. "Reflections on Gender and Technology Studies: In What State Is the Art?" Social Studies of Science 30 (3): 447-464.

Wajcman, J. 2009. "Feminist Theories of Technology." Cambridge Journal of Economics 34 (1): 143-152.

Zwarteveen, Margreet. 2011. "Questioning Masculinities in Water." Economic and Political Weekly 46 (18): 40-48.

Zwarteveen, Margreet, and V. Bennett. 2004. "The Connection between Gender and Water Management." In Opposing Currents: Gender and Water in Latin America, edited by V. Bennett, S. Dávila Poblete, and M. Nieves Rico, 13-29. Pittsburgh: University of Pittsburgh Press. 